\title{
Prosedur Administrasi Pelayanan Pemakaman Pada TPU Tegal Alur Unit II Islam Jakarta Barat
}

\author{
Akhmad Nurdiansyah ${ }^{1}$, Ria Andriani ${ }^{2}$, Dwi Puji Hastuti ${ }^{3}$ \\ ${ }^{1}$ Universitas Bina Sarana Informatika \\ e-mail: akhmadnurdiansyah07@gmail.com \\ ${ }^{2}$ Universitas Bina Sarana Informatika \\ e-mail: ria.rii@bsi.ac.id \\ ${ }^{3}$ Universitas Bina Sarana Informatika \\ e-mail: dwi.dsu@bsi.ac.id
}

Cara Sitasi: Nurdiansyah, A., Andriani, R., \& Hastuti, D. P. (2019). Prosedur Administrasi Pelayanan Pemakaman Pada TPU Tegal Alur Unit II Islam Jakarta Barat. Widya Cipta, 3(1), 149-156.

\begin{abstract}
The place funeral general which serves as a burial place for people who died. Funeral general also has other functions such as the Green Open Space, catchment area water, and lungs of the city. The author uses descriptive qualitative research methods. Sources of data in this study were obtained using the data used, interviews and documentation TPU Tegal Alur Unit II Islam which located in Jl.Kamal Raya No.1A. Kelurahan Tegal Alur. Kecamatan Kalideres. Kota Administrasi Jakarta Barat 11820. As well as interviews with that related source. The place funeral general tegal alur is a public cemetery that stands from the wakaf land owned by local residents. At the tomb was previously there is a tomb of Muslims and non-Muslims. TPU Tegal Alur Unit II Islam other than moving in service funeral, as providing information on funerals and retribution rates in general. TPU Tegal Alur Unit II Islam also one of the manufacturers for finance area ie within retribution service funeral.
\end{abstract}

Keywords: Procedure, Administration, Service

\section{PENDAHULUAN}

Saat ini banyak sekali investor yang berlombalomba untuk mendirikan bangunan-bangunan komersil. Akan tetapi dilihat dari luas wilayah kota Jakarta saat ini dan jumlah penduduk yang terus meningkat, kota Jakarta tidak memungkinkan untuk terus dilakukan pembangunan karena cukup sempit dan cukup padat. Oleh karena itu banyak lahan kosong yang harusnya dibiarkan hijau sudah menjadi beton bangunan-bangunan kokoh. Perkembangan di kota Jakarta diberbagai bidang seperti sektor ekonomi, sosial, maupun pariwisata membuat kota ini menjadi salah satu kota yang menarik untuk menjadi tujuan masyarakat dari kota sekitar untuk mencoba peruntungan atau mengadu nasib sehingga jumlah penduduk semakin meningkat dan kebutuhan akan lahan pemukiman warga kota Jakarta yang juga terus meningkat. Pembangunan tersebut sudah pasti akan berdampak terhadap tata guna lahan dan penambahan sarana perkantoran.

Salah satu fasilitas sosial yang ada di kota Jakarta adalah Tempat Pemakaman Umum (TPU) yang berfungsi sebagai tempat pemakaman bagi masyarakat yang meninggal dunia. Pemakaman umum juga memiliki fungsi lainnya seperti Ruang Terbuka Hijau (RTH), daerah resapan air, dan paruparu kota yang ditanami berbagai jenis tumbuhan.

Menurut Mukarom \& Wijaya Laksana (2016:97) standar pelayanan publik merupakan ukuran yang dibakukan dalam penyelenggaraan pelayanan publik yang wajib ditaati oleh pemberi atau penerima pelayanan sekurang-kurangnya meliputi berikut ini:

a. Prosedur pelayanan; dibakukan bagi pemberi dan penerima pelayanan termasuk pengaduan.

b. Waktu penyelesaian; ditetapkan sejak saat pengajuan permohonan sampai dengan penyelesaian, termasuk pengaduan.

c. Produk pelayanan; hasil pelayanan yang akan diterima sesuai dengan ketentuan yang telah ditetapkan.

d. Kopetensi petugas pemberi pelayanan; harus ditetapkan dengan tetap berdasarkan pengetahuan, keahlian, keterampilan, sikap dan perilaku yang diperlukan. 
Pelayanan pemakaman merupakan salah satu bentuk pelayanan pemerintah daerah yang sangat penting kepada masyarakat, yang wajib disediakan pelayanan pada pemakaman yang diberikan berupa pemberian informasi umum kepada masyarakat tentang ketentuan layanan pemakaman dan pemindahan atau pembongkaran makam serta melayani proses pelayanan tersebut.

Menurut J.S. Bowman dalam (Kussanti \& Leliana, 2017) "pelayanan publik merupakan lembaga rakyat yang memberi pelayanan kepada warga Negara, memperjuangkan kepentingan kolektif dan menerima tanggung jawab untuk memberi hasil”.

Menurut Ratminto dan Winarsih (2016:11) menyimpulkan bahwa "pelayanan publik atau pelayanan umum dapat didefinisikan sebagai segala bentuk jasa pelayanan, baik dalam bentuk barang publik maupun jasa publik yang pada prinsipnya menjadi tanggung jawab dan dilaksanakan oleh instansi pemerintah di pusat, daerah dan lingkungan dalam upaya memenuhi kebutuhan masyarakat"

Prosedur administrasi pemakaman merupakan suatu tahapan tentang proses penguburan jenazah dan pememberi informasi kepada masyarakat tentang ketentuan pemakaman dan pembongkaran makam ataupun pemindahan jenazah.

Menurut Fitzgerald, dkk dalam Umam ( 2014:151) mendefinisikan bahwa "Prosedur adalah urutanurutan yang tepat dari tahapan-tahapan instansi yang menerangkan apa yang harus dikerjakan, siapa yang mengerjakan, kapan mengerjakannya dan bagaimana mengerjakannya".

Menurut Mulyadi (2013:23) "Prosedur adalah suatu urutan kegiatan tulisa menulis, menggandakan, menghitung, membandingkan antara data sumber dengan dara pendukung kedua belah pihak”.

Atas dasar tujuan yang dilayani, menurut Rasto (2015a:50) prosedur dapat diklarifikasi menjadi dua jenis yaitu:

a. Prosedur Primer dimaksudkan untuk memperlancar penyelesaian pekerjaan seharihari.

Contoh jenis prosedur primer: prosedur pesanan, penagihan dan prosedur pembelian.

b. Prosedur sekunder dimaksud untuk memfasilitasi pekerjaan yang dilakaukan oleh prosedur primer.

Contoh jenis prosedur sekunder: prosedur surat menyurat, layanan telepon dan layanan arsip.

Tujuan yang ingin dicapai dalam penelitian tentang prosedur administrasi pelayanan pada TPU Tegal Alur Unit II Islam Jakarta Barat yakni untuk mengetahui dokumen-dokumen apa saja yang di gunakan dalam prosedur administrasi pelayanan pemakaman pada TPU Tegal Alur Unit II Islam Jakarta Barat dan untuk mengetahui kendala apa saja yang terjadi dan mengetahui bagaimanakah solusi untuk menangani kendala-kendala yang terjadi dalam pelaksanaan pelayanan.

Sedangkan manfaat dari penelitian ini yakni untuk menambah pengetahuan serta wawasan khususnya mengenai hal-hal yang berhubungan dengan prosedur administrasi pelayanan pemakaman pada TPU Tegal Alur Unit II Islam Jakarta Barat. Penelitian ini pun bisa menjadi bahan masukan atau informasi yang berguna dalam melaksanakan pelayanan pemakaman di TPU Tegal Alur Unit II Islam, untuk melakukan perbaikan ataupun peningkatan dalam melaksanakan prosedur adminitrasi pelayanan, sehingga dapat memperlancar pekerjaan.

\section{METODOLOGI PENELITIAN}

Metode penilitian yang digunakan dalam penelitian adalah penelitian deskriptif kualitatif. Menurut Sukadinata (2009:18) penelitian kualitatif adalah penelitian yang digunakan untuk mendeskripsikan dan menganalisis fenomena, peristiwa, aktivitas sosial, sikap kepercayaan, persepsi, dan orang secar indivisual maupun kelompok. Sedangkan deskriptif kualitatif dalam penelitian ini digunakan untuk mengembangkan teori yang dibangun melalui data yang diperoleh di lapangan. Metode kualitatif pada tahap awalnya melakukan penjajahan, selanjutnya melakukan pengumpulan data yang mendalam, mulai dari observasi samapai dengan penyusunan laporan.

Teknis penelitian in dilakukan dengan tiga tahap. Pertama observasi lapangan merupakan metode yang digunakan dalam penelitian ini karena penelitian ini lebih mengutamakan pengamatan langsung yakni pada TPU Tegal Alur Unit II Islam yang berada di Jl.Kamal Raya No.1A. Kelurahan Tegal Alur. Kecamatan Kalideres. Kota Administrasi Jakarta Barat 11820.

Tahap kedua yakni metode wawancara yang dimana penulis melakukan pengumpulan data dan memperoleh informasi dari pengelola TPU langsung sehingga data yang diperoleh valid untuk dijadikan bahan penelitian. Tahap ketiga penulis menggunakan metode dokumentasi dengan cara melampirkan dokumen-dokumen pendukung sebagai bukti dari hasil penelitian mengenai prosedur adminitrasi pelayanan makam pada TPU Tegal Alur Unit II Islam Jakarta Barat.

Tahap ketiga yakni metode dokumentasi yang mana penulis memperoleh data perlengkapan dengan cara 
melampirkan dokumen-dokumen pedukung sebagai bukti dari hasil penelitian mengenai prosedur administrasi pelayanan makan pada TPU Tegal Alur Uniut II Jakarta barat.

\section{HASIL DAN PEMBAHASAN}

1. Dokumen-Dokumen yang digunakan Dalam Prosedur Administrasi Pelayanan Pemakaman TPU Tegal Alur Unit II Islam Jaarta Barat

Tabel 1. Persyaratan Pengajuan Pelayanan Pemakaman di TPU Tegal Alur Unit II Islam

\begin{tabular}{|c|c|c|}
\hline No & $\begin{array}{c}\text { Jenis } \\
\text { pelayanan }\end{array}$ & Syarat \\
\hline 1 & Makam baru & $\begin{array}{l}\text { 1. Fotokopi KTP ahli waris. } \\
\text { 2. Fotokopi KTP } \\
\text { almarhum. } \\
\text { 3. Fotokopi Kartu Keluarga } \\
\text { almarhum. } \\
\text { 4. Surat pengantar RT dan } \\
\text { RW. } \\
\text { 5. Surat keterangan } \\
\text { kematian dari rumah } \\
\text { sakit atau puskesmas. } \\
\text { 6. Surat keterangan } \\
\text { kematian dari kelurahan } \\
\text { sesuai domisili. }\end{array}$ \\
\hline 2 & $\begin{array}{l}\text { Makam } \\
\text { tumpang }\end{array}$ & $\begin{array}{l}\text { 1. Membawa surat IPTM } \\
\text { (asli) makam yang ingin } \\
\text { ditumpang. } \\
\text { 2. Fotokopi Kartu Keluarga } \\
\text { almarhum. } \\
\text { 3. Surat pengantar RT dan } \\
\text { RW. } \\
\text { 4. Fotokopi KTP almarhum. } \\
\text { 5. Fotokopi KTP ahli waris. } \\
\text { 6. Surat keterangan } \\
\text { kematian dari rumah } \\
\text { sakit atau puskesmas. }\end{array}$ \\
\hline 3 & $\begin{array}{l}\text { Perpanjang } \\
\text { surat Ijin } \\
\text { Pengunaan } \\
\text { Tanah } \\
\text { Makam } \\
\text { IPTM }\end{array}$ & $\begin{array}{l}\text { 1. Membawa surat IPTM } \\
\text { (asli). } \\
\text { 2. Fotokopi KTP ahli waris. }\end{array}$ \\
\hline 4 & $\begin{array}{l}\text { Pemakaman } \\
\text { jenazah } \\
\text { terlantar, } \\
\text { tidak } \\
\text { diketahui ahli } \\
\text { waris atau } \\
\text { tanpa } \\
\text { identitas }\end{array}$ & $\begin{array}{l}\text { 1. Surat dari Dinas Sosial } \\
\text { atau dari RSCM perihal } \\
\text { surat permohonan } \\
\text { pemakaman. } \\
\text { 2. Surat permohonan } \\
\text { menggunakan mobil } \\
\text { jenazah untuk angkat } \\
\text { jenazah terlantar. }\end{array}$ \\
\hline
\end{tabular}

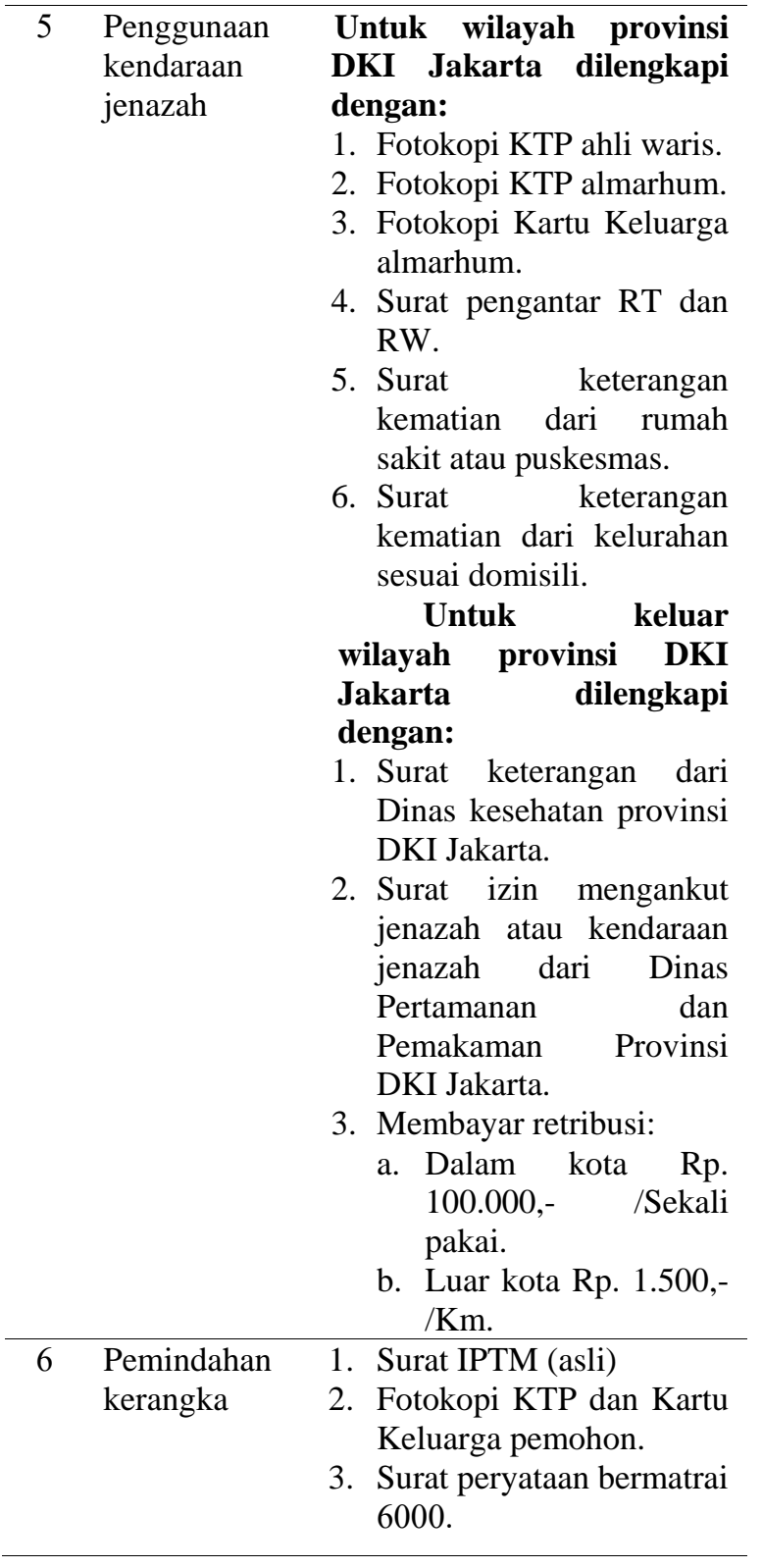

\section{A. Prosedur Pelayanan Pemakaman pada TPU Tegal Alur Unit II Islam Jakarta Barat}

Prosedur pelayanan untuk makam baru dan makam tumpang pada TPU Tegal Alur Unit II Islam berawal dari proses pendaftaran hingga proses mendapatkan surat IPTM (Ijin Penggunaan Tanah Makam), akan dijelaskan sebagai berikut:

\section{Prosedur Pelayanan Makam Baru}




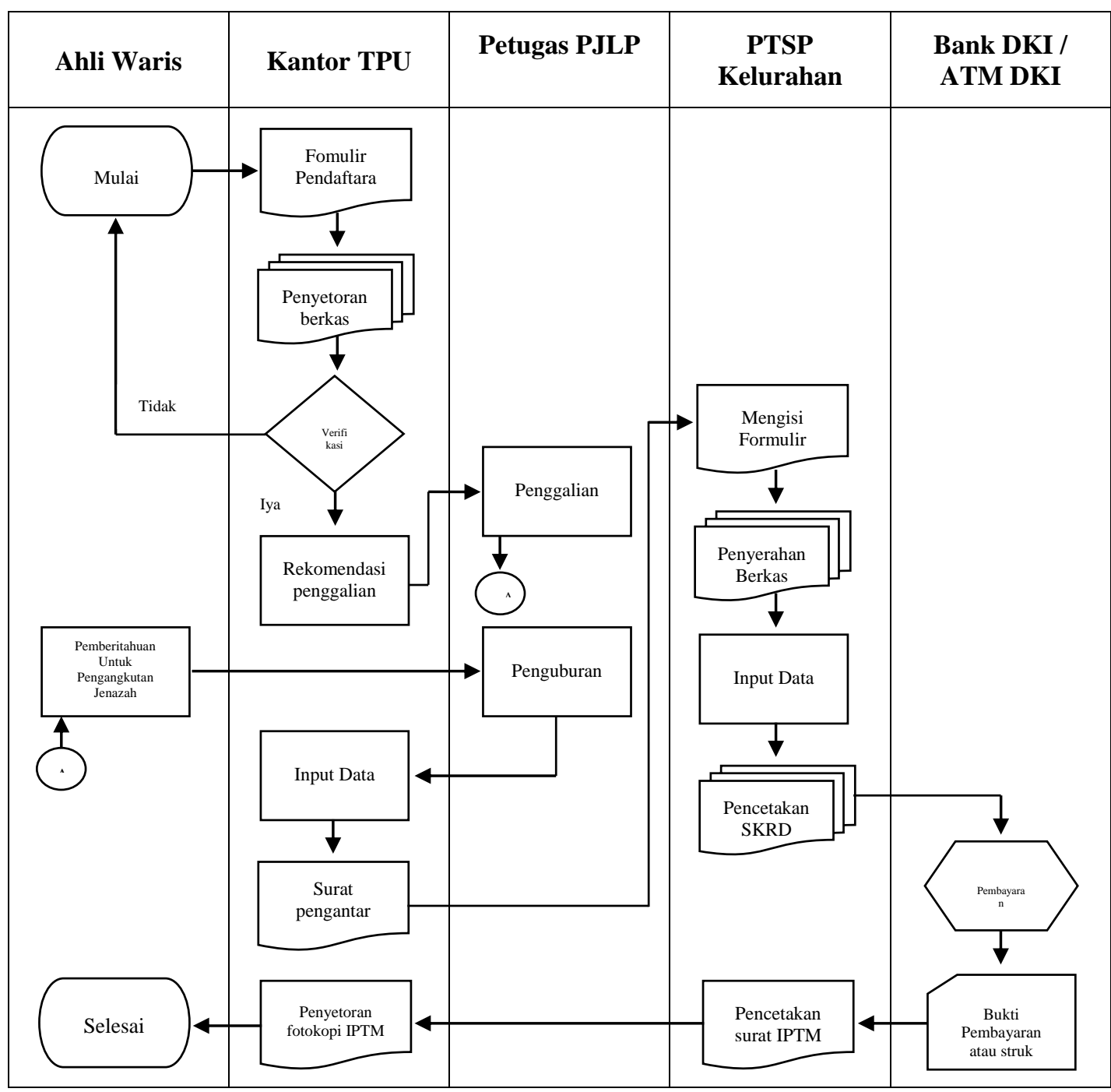

Sumber: TPU Tegal Alur Unit II Islam

Gambar 1. Alur Prosedur Pelayanan Makam Baru

a. Ahli waris.

Ahli waris datang ke kantor TPU melakukan pendaftaran dengan mengisi formulir pendaftaran makam baru dan menyipkan dokumen-dokumen yang diperlukan seperti:

1) Fotokopi KTP almarhum ber-KTP DKI sesuai Peratuan Daerah Nomor 3 Tahun 2007 Tentang Pemakaman.

2) Fotokopi KTP ahli waris.

3) Fotokopi KK (Kartu Keluarga).

4) Fotokopi surat keterangan kematian dari puskesmas.

5) Fotokopi surat keterangan dari kelurahan.

6) Surat pengantar dari RT dan RW.

Dokumen tersebut disiapkan sebanyak dua rangkap. Satu rangkap untuk diserahkan ke kantor TPU untuk pendaftaran makam baru, satu rangkap lagi untuk pembuatan surat IPTM (Ijin Penggunaan Tanah Makam) ke PTSP kelurahan dan dengan dilengkapi dengan surat pengantar dari TPU (Tempat Pemakaman Umum) setelah proses pemakaman selesai.

b. Kantor TPU (Tempat Pemakaman Umum). Administrasi kantor TPU (Tempat Pemakaman Umum) melakukan pemeriksaan dokumen. Setelah pemeriksaan dokumen dinyatakan lengkap dan memenuhi syarat. Administrasi kantor TPU (Tempat Pemakaman Umum) mengeluarkan surat rekomendasi penggalian makam ke petugas PJLP (Penyedia Jasa Lainnya Perorangan) untuk melakukan proses penggalian.

\section{c. Petugas PJLP (Penyedia Jasa Lainnya Perorangan).}

Petugas PJLP (Penyedia Jasa Lainnya Perorangan) melakukan proses penggalian pada blok dan petak 
makam sesuai surat rekomendasi yang telah diberikan.

\section{d. Ahli Waris.}

Selama proses penggalian berlangsung ahli waris diperbolehkan pulang untuk memberi kabar keluarga dan membawa jenazah ke lokasi penggalian makam sekaligus untuk proses penguburan. Petugas PJLP (Penyedia Jasa Lainnya
Perorangan).

Setelah proses penguburan selesai petugas PJLP (Pelayanan Jasa Lainnya Perorangan ) mengarahkan ahli waris untuk melapor ke kantor TPU (Tempat Pemakman Umun) untuk diberi pengarahan selanjutnya.

\section{f. Kantor TPU (Tempat Pemakaman Umum).}

Administrasi kantor TPU (Tempat Pemakaman Umum) melakukan proses penginputan data dan pencetakan surat pengantar untuk melengkapi dokumen yang akan diserahkan ke pada PTSP kelurahan sesuai domisili.

\section{g. PTSP Kelurahan.}

Ahli waris datang ke PTSP kelurahan mengisi formulir bermatrai serta melampirkan dokumen yang sudah dilengkapi dengan surat pengantar dari TPU (Tempat Pemakaman Umum). Petugas PTSP (Pelayanan Terpadu Satu Pintu) melakukan penginputan data yang telah diserahkan untuk pencetakan SKRD (Surat Keterangan Retribusu Daerah). Setelah memperoleh SKRD (Surat Keterangan Retribusi Daerah) ahli waris diwajibkan melakukan proses pembayaran sesuai blok petak makam yang digunakan sebagai berikut:

Tabel .2 Biaya Retribusi Makam Baru No Blok Makam Baru

\begin{tabular}{lll}
\hline 1 & AAI & Rp. $100.000,-$ \\
\hline 2 & AAII & Rp. $80.000,-$ \\
\hline 3 & AI & Rp. $60.000,-$ \\
\hline 4 & AII & Rp. $40.000,-$ \\
\hline
\end{tabular}

Sumber: TPU Tegal Alur Unit II Islam

h. Bank DKI atau ATM DKI.

Ahli waris dapat melakukan proses pembayaran SKRD (Surat Keterangan Retribusi Daerah) dengan dua cara metode pembayaran, antara lain sebagai berikut:

1) Metode pembayaran melalui mesin ATM DKI.

a) Pilih menu pembayaran. b) Pilih Virtual Account.

c) Masukan Virtual Account 998003 + No.SSRD (Surat Setoran Retribusi Daerah).

d) Kode pembayaran dikosongkan lalu pilih lanjut.

2) Metode pembayaran melalui SKRD Bank DKI.

Setelah proses pembayaran telah dilakukan. Ahli waris melakukan menyetor bukti pembayaran SKRD (Surat Keterangan Retribusi Daerah) berupa struk atau SKRD (Surat Keterangan Retribusi Daerah) yang sudah distempel dan nyatakan lunas oleh pihak Bank DKI.

i. PTSP Kelurahan.

Petugas PTSP (Pelayanan Terpadu Satu Pintu) menerima bukti pembayaran SKRD (Surat Keterangan Retribusi Daerah) untuk melakukan proses pencetakan surat IPTM (Ijin Penggunaan Tanah Makam) dan penyerahan surat IPTM (Ijin Penggunaan Tanah Makam) ke pihak ahli waris.

j. Kantor TPU.

Ahli waris mendatangi kantor TPU (Tempat Pemakaman Umun) untuk melakukan penyetoran fotokopi surat IPTM (Ijin Penggunaan Tanah Makam).

k. Ahli Waris.

Mendapatkan surat IPTM (Ijin Penggunaan Tanah Makam) makam baru.

\section{Prosedur Pelayanan Makam Tumpang}

Alur prosedur persis seperti makam baru namun hanya ada penambahan di surat IPTM asli dan biaya retribusi sebagai berikut:

Tabel 3. Biaya Retribusi Makam Tumpang

\begin{tabular}{ccc}
\hline No & Blok & Makam Baru \\
\hline 1 & AAI & Rp. 25,000,- \\
\hline 2 & AAII & Rp. 20.000,- \\
\hline 3 & AI & Rp. 15.000,- \\
\hline 4 & AII & Rp. 10.000,- \\
\hline
\end{tabular}




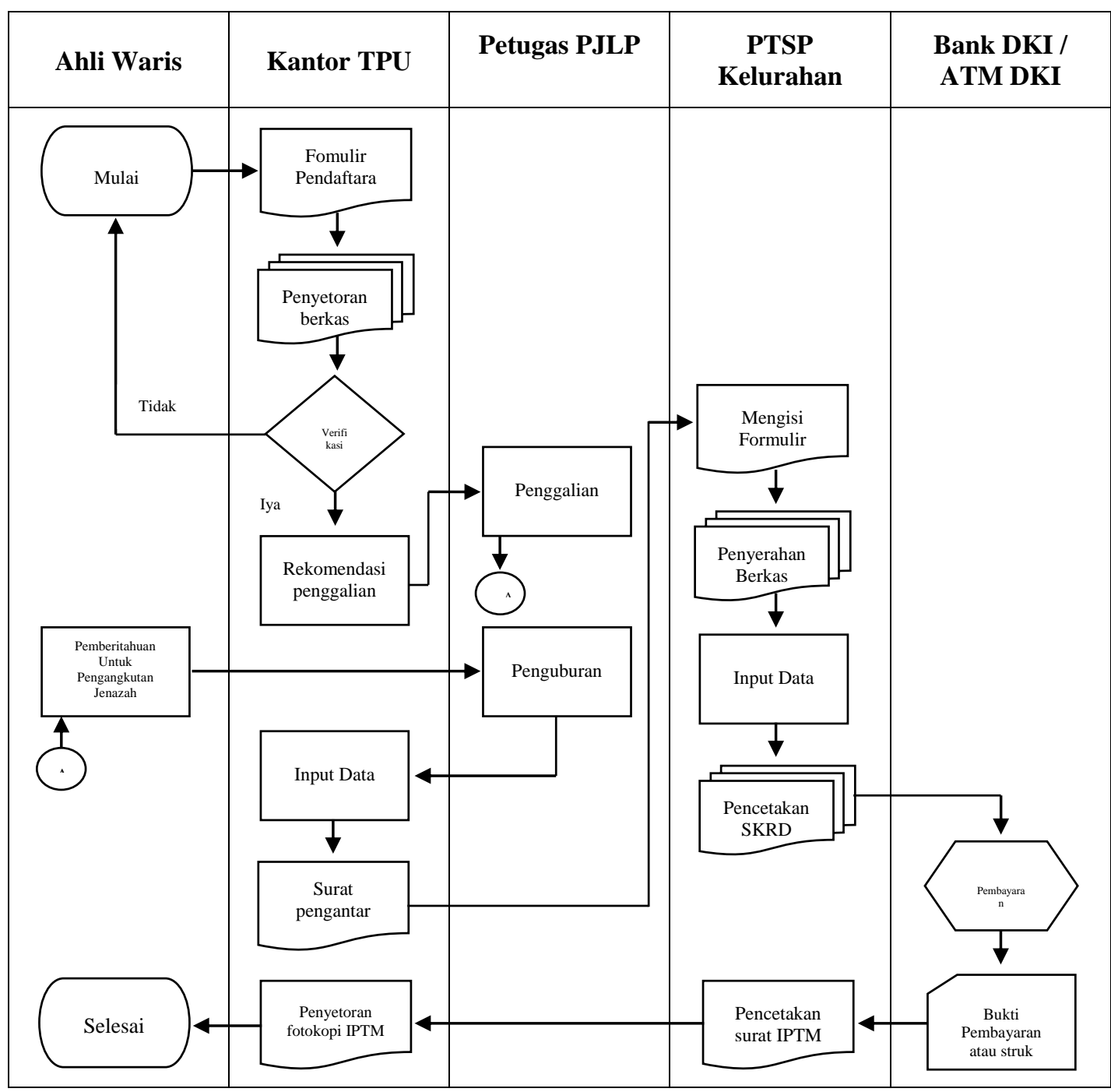

Gambar 2. Alur Prosedur Pelayanan Makam Tumpang

Sumber: TPU Tegal Alur Unit II Islam

2 Kendala yang Terjadi dalam Pelaksanaan Pelayanan Pada TPU Tegal Alur Unit II Islam Jakarta Barat

Dalam proses adminitrasi pelayanan pemakaman ada kendala yang dimana menghambat proses pelayanan pemakaman pada TPU Tegal Alur Unit II Islam antara lain:

a. Ahli waris kurang pengetahuan tentang prosedur pemakaman.

Masih ada masyarakat yang belum mengerti akan prosedur pemakaman pada TPU Tegal Alur Unit II Islam sehingga masih banyak ahli waris yang tidak mau mengikuti prosedur pemakaman yang berlaku.

b. Tanah keras dalam proses penggalian.

Tanah yang keras dapat menghambat dalam proses penggalian, sehingga dapat memakan waktu yang cukup lama. c. Ahli waris kehilangan surat IPTM (Izin Penggunaan Tanah Makam).

Hilangnya surat IPTM (Izin Penggunaan Tanah Makam) menjadi masalah bagi ahli waris dikarenakan tidak dapat memperpanjang masa berlaku penggunaan tanah makam.

d. Ahli waris lupa petak makam.

Banyak dari pihak ahli waris bingung dan pusing karna lupa akan lokasi petak pada makam dikarenakan ahli waris takut makam sudah tidak ada, tertindih dengan makam baru.

e. Pungutan liar yang mengatas namakan TPU Tegal Alur Unit II Islam.

Seringkali terjadi pungutan liar mengatas namakan pihak pegawai PJLP (Penyedia Jasa Lainnya Perorangan) maupun instansi agar dari pihak diluar instansi atau PJLP (Penyedia Jasa Lainnya 
Perorangan) mendapatkan sejumlah uang yang mereka inginkan.

3. Solusi untuk Menangani Kendala-kendala yang terjadi dalam pelaksanaan pemakaaman pada TPU Tegal Alur Unit II Islam Jakarta Barat

Dalam mengatasi kendala yang sering terjadi dalam pelaksanaan pelayanan pemakaman, maka pihak TPU Tegal Alur Unit II Islam mengadakan evaluasi dan perbaikan agar pelayanan berlangsung dengan lancar. Dari setiap kendala dapat diuraikan sebagai berikut untuk mengatasinya:

a. Kurangnya pengetahuan tentang prosedur pemakaman

Petugas TPU Tegal Alur memberikan informasi secara langsung maupun tidak langsung terhadap masyarakat dengan cara melakukan pemasangan banner dan kertas berupa prosedur terkait tentang pemakaman serta nomor telepon petugas kantor itu sendiri terkait untuk bagian informasi.

b. Tanah yang keras dalam proses penggalian makam.

Agar tanah menjadi tidak keras dalam proses penggalian dapat dilakukan dengan cara menyiram dibagian tanah yang keras agar tanah menjadi sedikit lunak dalam proses pengalian.

c. Ahli waris kehilangan surat IPTM (Izin Penggunaan Tanah Makam).

Petugas akan melakukan mengecekan petak makam secara manual atau dengan cara menggunakan komputer setelah blok dan petak makam ditemukan pihak administrasi melakukan pencetakan surat pengantar, untuk peroses selanjutnya petugas akan mengarahkan ahli waris untuk melapor kekepolisian setempat untuk membuat surat kehilangan petak makam dan lanjut mengurus pembuatan surat IPTM baru di kelurahan setempat.

\section{d. Ahli waris lupa petak makam.}

Petugas dapat melakukan dengan cara pengecekan melalui komputer, pengecekan secara manual dan pengecekan secara langsung.

e. Pungutan liar yang mengatas namakan TPU Tegal Alur Unit II Islam.

Memberi informasi kepada masyarakat agar melapor ke pihak kantor TPU jika diminta uang diluar prosedur pemakaman dan seluruh pihak pegawai maupun instansi lebih berhati-hati dan memperketat keamanan.

\section{KESIMPULAN}

Bedasarkan pembahasan diatas maka penulis dapat menarik kesimpulan sebagai berikut:

1. TPU Tegal Alur sudah ada sekitar \pm tahun 1950 yang berdiri ditanah wakaf milik warga setempat yang terdapat makam muslim maupun non muslim. Pada tahun 1974 Tempat pemakaman umum (TPU) Tegal Alur diambil alih oleh pemerintah daerah dan dikelola hingga sakarang.

2. TPU Tagal Alur Unit II Islam yang berfungsi sebagai tempat pemakaman bagi masyarakat yang meninggal dunia. Pemakaman umum juga memiliki fungsi lainnya seperti Ruang Terbuka Hijau (RTH), daerah resapan air, dan paru-paru kota yang ditanami berbagai jenis tumbuhan.

3. TPU Tegal Alur Unit II Islam selain bergerak dalam bidang pelayanan pemakaman, sebagai memberi informasi tentang pemakaman dan tarif retribusi secara umum. TPU Tegal Alur Unit II Islam juga merupakan salah satu penghasil bagi keuangan daerah yakni dalam melaksanakan retribusi pelayanan pemakaman.

4. Pengelolaan yang dilakukan oleh pihak pengelolaan dan kualitas sumber daya manusia (pegawai) masih relatif rendah menjadi kondisi TPU Tegal Alur Unit II Islam kurang nyaman, tertib dan indah.

\section{REFERENSI}

Fahmi, Irham. 2015. Pengantar Ilmu Administrasi Bisnis. Bandung: Alfabeta

Kussanti, D. P., \& Leliana, I. (2017). Dampak Program Dinas Penanaman Modal dan Pelayanan Terpadu Satu Pintu ( DPMPTSP) Walikota Depok Bagi Masyarakat, VIII(September), 121-125.

Mukarom \& Wijaya Laksana. 2016. Membangun Kinerja Pelayanan Publik. Jakarta: CV Pustaka Setia

Rasto. 2015. Manajeman Perkantoran. Bandung: Alfabeta.

Ratminto \& Winarsih. 2016. Manajeman Pelayanan. Jogjakarta: Pustaka Pelajar.

Siswandi. 2017. Administrasi Logistik \& Gudang (Kasus dan Aplikasi Perusahaan)

Umam, Khaerul. 2014. Manajeman Perkantoran. Bandung: Pustaka Setia. 


\section{PROFIL PENULIS}

Akhmad Nurdiansyah, A.Md adalah seorang mahasiswa Universitas Bina Sarana Informatika jurusan Administrasi Bisnis dan sudah lulus.

Ria Andriani, SM adalah seorang tenaga pengajar di Administrasi Bisniss, Fakultas Ekonomi dan Bisnis, Universitas Bina Sarana Informatika. Pendidikan Strata 1 jurusan Manajemen, Institut Bisnis Informatika Kosgoro 1957. Pada Saat ini sedang menempuh pendidikan Strata 2 di Universitas Budi Luhur dengan Jurusan Manajemen.

Dwi Puji Hastuti, SS adalah seorang tenaga pengajar bahasa Inggris, Fakultas Komunikasi dan Bahasa , Universitas Bina Sarana Informatika. Pendidikan Strata 1 jurusan Sastra Inggris, STIBA Nusa Mandiri. Pada Saat ini sedang menempuh pendidikan Strata 2 di Universitas Indraprasta PGRI dengan jurusan Pendidikan Bahasa Inggris. 